\title{
Rentabilidade da exploração leiteira em uma propriedade durante cinco anos
}

\author{
[Five-year profitability in a dairy farm] \\ E. Prado ${ }^{1}$, L.G. Geraldo ${ }^{2}$, B.M. Cardoso ${ }^{3}$ \\ ${ }^{1}$ Escola de Veterinária - UFMG \\ Caixa Postal 567 \\ 30123-970 - Belo Horizonte, MG \\ ${ }^{2}$ EMATER - Belo Horizonte, MG \\ ${ }^{3}$ Aluno de graduação - EV-UFMG - Belo Horizonte, MG
}

\begin{abstract}
RESUMO
Estudou-se a rentabilidade da atividade bovina leiteira em uma fazenda no município de JaboticatubasMG, durante cinco anos - 1996, 2000, 2001, 2002 e 2003. Os dados foram processados no Sistema de Administração Rural e Projetos Agropecuários da EMATER-MG. No cômputo global, conforme valores de dezembro de 2003, a margem líquida negativa atingiu R $\$-201.091,89$, embora a margem bruta fosse positiva ( $R \$ 130.003,54)$. O custo da mão-de-obra foi o que mais onerou a produção $(29,6 \%)$ e o que mais forçou a elevação dos custos fixos $(47,8 \%)$. O custo unitário do litro de leite alcançou R $\$ 0,71$, enquanto o preço recebido pelo produtor atingiu apenas $\mathrm{R} \$ 0,50$. Isso significa que durante o período analisado houve prejuízo de $\mathrm{R} \$ 0,21$ em cada litro de leite produzido.
\end{abstract}

Palavras-chave: bovinos de leite, rentabilidade, custo de produção

\begin{abstract}
The profitability of a dairy farm, in Jaboticatubas-MG, was studied during five years - 1996, 2000, 2001, 2002 e 2003. The collected data were processed using the EMATER-MG Rural Administration System and Agricultural Projects. In general, the damages were $R \$-201,091.89$, although the incomes were enough to pay the variable costs and to be left out $R \$ 130,003.54$. Employees payment was the highest cost of the production (29.6\%) and it forced the fixed costs to high (47.8\%) The unitarian cost of the liter of milk reached $R \$ 0.71$, while the farmer sold it for $R \$ 0.50$. That means losses of $R \$ 0.21$ for each liter during all the time of the study. Global results showed $R \$ 0.71$ for the cost of a liter of milk, although it was paid just $R \$ 0.50$. That means damages about $R \$ 0.21$ for each liter of milk produced for such long time.
\end{abstract}

Keywords: dairy cattle, profitability, production cost

\section{INTRODUÇÃO}

Dentro do quadro atual de competitividade, fomentada pela desregulamentação dos mercados nas fronteiras internacionais, a pecuária bovina leiteira no Brasil, a perdurarem as condições vigentes, corre riscos de enfrentar descontinuidades e graves retrocessos. Este cenário, confrontado com as perspectivas de futuro, tem motivado a realização de estudos de custo de produção com a finalidade de revelar a real situação econômica das explorações, para que produtores, técnicos e políticos possam se orientar nas tomadas de decisões.

De acordo com Reis (1996), a adoção da prática da contabilidade rural permite entender melhor $\mathrm{e}$ racionalizar as atividades da propriedade $\mathrm{e}$ possibilita avaliar índices técnicos e econômicos, identificar pontos de estrangulamento e

Recebido em 28 de abril de 2005

Aceito em 18 de dezembro de 2006

E-mail: erly@vet.ufmg.br 
determinar os fatores que interferem no processo de produção.

Em estudo de desempenho técnico-econômico na bacia leiteira de Divinópolis-MG, Prado et al. (1995) constataram prejuízos econômicos em propriedades que apresentavam bons níveis de produção e produtividade. A causa principal dos prejuízos, segundo informaram, residia na deficiência gerencial, motivada pelo desconhecimento de indicadores zootécnicos e econômicos.

Guimarães e Madalena (2003) insistiram na necessidade de se contemplar os aspectos econômicos na análise comparativa de sistemas de produção, uma vez que sistemas com indicadores zootécnicos mais elevados podem apresentar indicadores econômicos inferiores.

Reis (2001) advertiram para o fato de que os produtores necessitam exercer o controle daquelas variáveis que estão a seu alcance, já que não dispõem de mecanismos que lhes possibilitem interferir nos preços recebidos.

O objetivo deste trabalho foi determinar os custos de produção e a rentabilidade da atividade leiteira em uma propriedade durante cinco anos.

\section{MATERIAL E MÉTODOS}

A pesquisa foi desenvolvida na Fazenda Águas Limpas, de propriedade de José Maximiano Vieira, no município de Jaboticatubas-MG, situada a $85 \mathrm{~km}$ de Belo Horizonte.

O estudo foi realizado nos anos de 1996, 2000, 2001, 2002 e 2003. Definiu-se o ano-calendário, isto é, de janeiro a dezembro, como o período a ser analisado. O primeiro, 1996, foi realizado de forma retrospectiva, ou seja, após o término do período catalogaram-se todos os dados e produziu-se uma série de indicadores que retratavam a situação técnica e econômica da atividade. A partir daí, aguardou-se pela decisão do proprietário, e depois, pelas reestruturações a que tinha proposto empreender antes de dar continuidade à avaliação dos custos. Esse interregno durou três anos, quando foram ministradas, esporadicamente, orientações técnicas e organizacionais ao produtor, para que ele corrigisse os pontos de estrangulamento constatados na exploração.
Nos períodos subseqüentes, paralelamente às atividades de contabilização, realizadas no decorrer de cada período, continuaram os ajustes e orientações, até que, no final de 2003, o produtor decidiu encerrar a atividade. Portanto, esses foram os fatores que limitaram o período de abrangência do estudo.

Os dados obtidos em visitas periódicas, de documentos e dos próprios registros da fazenda foram sistematizados em formulários próprios do Sistema de Administração Rural e Projetos Agropecuários (SARPA), da Empresa de Assistência Técnica e Extensão Rural do Estado de Minas Gerais, um sistema de estudo técnico e econômico da propriedade rural elaborado por Reis (1996).

Os formulários, encaminhados ao SARPA, foram processados para produzir os indicadores técnicos e econômicos requeridos. As análises processadas são de caráter descritivo.

Os indicadores técnicos e econômicos foram calculados segundo a metodologia proposta por Reis (1996).

As depreciações foram calculadas pelo método linear, com agregação de valor residual. A remuneração de capital semi-fixo compreende uma modalidade de custo de oportunidade e é calculada aplicando-se a taxa de remuneração da poupança oficial $(6 \%)$ sobre o valor de máquinas, equipamentos, veículos e animais. Calcula-se a conservação de máquinas, equipamentos, veículos e benfeitorias aplicando um percentual de $2,5 \%$ aos valores correspondentes, relacionados no inventário. O valor da produção configura receitas provenientes da venda de leite, animais, esterco e ainda a diferença de inventário. Todos os valores foram convertidos em litros de leite, com base nos preços recebidos. Todos os custos foram calculados dividindo-se a modalidade de custo pelo total da produção.

Para facilitar a compreensão dos resultados e poder compará-los entre si, converteram-se todos os dados econômicos em moeda corrente, atualizados para dezembro de 2003, tomando-se como parâmetro o índice geral de preços disponibilidade interna (IGP-DI). Esse índice tem por objetivo balizar o comportamento de preços, em geral, na economia e refere-se ao mês 
cheio, ou seja, o período de coleta vai do primeiro ao último dia do mês de referência.

O resultado da rentabilidade foi calculado reunindo todos os períodos de análise após a atualização.

\section{RESULTADOS E DISCUSSÃO}

A Tab. 1 especifica a composição dos custos de todos os anos pesquisados em valores atualizados para dezembro de 2003. Observa-se que há uma certa equivalência entre custos varáveis $(48,7 \%)$ e custos fixos $(47,7 \%)$. Essa aproximação exige um exame especial, sob suspeição de se tratar de uma estrutura de produção não muito eficiente. Não se pode, por exemplo, comparar esses dados com aqueles relatados por Reis et al. (2001), configurados respectivamente em $76,4 \%$ e 23,6\%. A dificuldade de comparação reside na diferença de critérios empregados na classificação dos fatores de produção em variáveis e fixos. É pertinente compará-los com os indicadores apontados por Prado et al. (1995), uma vez que foram produzidos obedecendo aos mesmos critérios classificatórios. Naquele estudo, realizado em 30 propriedades rurais, a distribuição entre custos variáveis e fixos correspondeu a $55,9 \%$ e $44,1 \%$ respectivamente para os estratos mercantil simples, préempresário e empresário. Assim, tendo por referência esses registros, constata-se que os custos fixos encontrados no presente trabalho apresentam-se elevados. O fator de maior peso na determinação desses percentuais é a mão-deobra permanente, que corresponde a $24,4 \%$ do custo total e a mais da metade dos custos fixos. Se se considerar o total da mão-de-obra (variável e fixa), esta representa quase $30 \%$ do custo total do litro de leite. A razão para um tão alto emprego de mão-de-obra prende-se ao fato de se tratar de uma propriedade em regime de semiconfinamento. Assim, a comparação realizada também perde sentido, e não se pode tomar a equivalência anterior como uma anormalidade. $\mathrm{O}$ segundo aspecto que pressiona a elevação dos custos fixos, e que à observação empírica se mostra superdimensionado, engloba as benfeitorias, máquinas e equipamentos.

Tabela 1. Custos de produção de leite bovino na fazenda Águas Limpas, no município de Jaboticatubas MG, relativos aos anos de 1996, 2000, 2001, 2002 e 2003

\begin{tabular}{|c|c|c|c|c|c|c|c|}
\hline Especificação & 1996 & 2000 & 2001 & 2002 & 2003 & TOTAL & $\%$ Geral \\
\hline Alimentação & $13.406,88$ & $49.383,84$ & $41.380,36$ & $46.374,78$ & $38.955,41$ & $189.501,27$ & 27,33 \\
\hline Mistura mineral & $2.235,07$ & $3.469,38$ & $2.920,67$ & $2.120,20$ & $2.677,80$ & $13.423,11$ & 1,94 \\
\hline Vacinas & 891,45 & 830,42 & 259,09 & 943,15 & 38,90 & $2.963,01$ & 0,42 \\
\hline Medicamentos & $1.751,27$ & $5.461,01$ & $6.701,44$ & $7.618,86$ & $5.579,84$ & $27.112,42$ & 3,91 \\
\hline Carrapaticida & 362,40 & 775,04 & 589,25 & 222,42 & 228,80 & $2.177,91$ & 0,31 \\
\hline Vermífugo & 172,24 & 104,44 & 52,70 & 277,46 & 299,05 & 905,89 & 0,13 \\
\hline Serviços profissionais & & 425,84 & 782,88 & 411,31 & 101,08 & $1.721,11$ & 0,25 \\
\hline Transporte & $2.031,70$ & $3.420,43$ & $4.138,52$ & $3.282,15$ & $2.582,27$ & $15.455,08$ & 2,23 \\
\hline Mão-de-obra variável & $4.347,27$ & $8.120,47$ & $14.286,40$ & $3.922,28$ & $4.955,98$ & $35.632,41$ & 5,14 \\
\hline Impostos, taxas & 677,22 & $2.400,39$ & $2.280,01$ & $1.688,46$ & $1.190,29$ & $8.236,36$ & 1,19 \\
\hline Energia elétrica & $1.458,14$ & $2.855,72$ & $1.208,22$ & $1.832,56$ & $1.852,17$ & $9.206,81$ & 1,33 \\
\hline Combustível & $3.132,68$ & $2.891,48$ & $2.336,38$ & $2.850,28$ & $2.271,70$ & $13.482,53$ & 1,94 \\
\hline Conservação máq., veículos e equip. & $1.729,26$ & $1.659,38$ & $1.234,53$ & $1.394,54$ & $1.056,24$ & $7.073,94$ & 1,02 \\
\hline Sêmen & & 721,38 & 146,14 & 318,82 & & $1.186,35$ & 0,17 \\
\hline Outras despesas & & $2.429,24$ & & $5.930,14$ & $1.478,11$ & $9.837,49$ & 1,43 \\
\hline Custos variáveis & $32.195,56$ & $84.948,57$ & $81.966,63$ & $79.187,42$ & $63.267,64$ & $337.915,69$ & 48,73 \\
\hline Custos de oportunidade & $1.636,52$ & $3.777,68$ & $4.198,72$ & $13.060,80$ & $1.700,90$ & $24.374,61$ & 3,52 \\
\hline $\begin{array}{l}\text { Depreciação forragens perenes para } \\
\text { corte }\end{array}$ & & & 583,28 & $6.962,28$ & 371,43 & $7.916,99$ & 1,14 \\
\hline Depreciação pastagem cultivada & $9.608,89$ & $3.904,03$ & $3.383,02$ & $2.871,02$ & $2.583,33$ & $22.350,29$ & 3,22 \\
\hline Depreciação benfeitorias & $5.287,06$ & $2.413,92$ & $7.860,35$ & $6.535,58$ & $3.659,77$ & $25.756,68$ & 3,71 \\
\hline Conservação de benfeitorias & $6.709,58$ & $4.019,56$ & $3.421,93$ & $2.748,64$ & $2.550,00$ & $19.449,71$ & 2,81 \\
\hline Depreciação de máq., veículos e equip. & $9.628,21$ & $6.040,30$ & $5.483,52$ & $6.962,28$ & $4.868,33$ & $32.982,63$ & 4,76 \\
\hline Mão-de-obra permanente familiar & $13.903,56$ & $11.435,09$ & $10.289,07$ & $15.503,48$ & $17.280,00$ & $68.411,20$ & 9,87 \\
\hline Mão-de-obra contratada & $25.026,40$ & $18.304,31$ & $18.343,94$ & $21.188,08$ & $18.144,00$ & $101.006,74$ & 14,57 \\
\hline Remuneração do capital & $10.711,30$ & $10.710,26$ & $11.240,81$ & $11.423,22$ & $9.135,60$ & $53.221,19$ & 7,68 \\
\hline Custos fixos & $80.875,00$ & $56.827,48$ & $60.605,92$ & $67.662,94$ & $58.592,46$ & $331.095,42$ & 47,75 \\
\hline Custos totais & $113.070,56$ & $141.776,05$ & $142.572,55$ & $146.850,36$ & $121.860,10$ & $693.385,72$ & 100,00 \\
\hline
\end{tabular}

Obs.: valores atualizados para dezembro/2003, pelo IGP-DI da FGV. 
O resultado final, no agregado de todos os anos, apresentou custo unitário do litro de leite de R\$ 0,71 . É interessante destacar que o preço recebido pelo produtor ficou aquém desse valor, atingindo apenas $\mathrm{R} \$ 0,50$. A par dessa discrepância, constata-se que, durante o longo período analisado, houve um prejuízo da ordem de $\mathrm{R} \$ 0,21$ em cada litro de leite produzido. Entretanto, deve ater-se que, malgrado os resultados desfavoráveis, a atividade apresenta margem bruta (valor da produção menos custos variáveis) positiva. Isso significa que o custeio da atividade está sendo reembolsado. O problema, assim, concentra-se na remuneração dos custos fixos, que só parcialmente são cobertos. É por isso que a margem líquida (valor da produção menos custos totais) apresenta-se negativa. A perdurar essa situação que, com efeito, constitui um processo de descapitalização, uma vez que se fica impossibilitado de realizar a reposição de bens de capital, a atividade tende, em longo prazo, a inviabilizar-se, o que de fato aconteceu, como mencionado anteriormente (Tab. 2). As conclusões de Reis (2001) apontam essa mesma problemática. Semelhantemente o fazem Prado et al. (1995).

Tabela 2. Resultados econômicos da exploração bovina leiteira da Fazenda Águas Limpas, município de Jaboticatubas-MG, relativos aos anos de 1996, 2000, 2001, 2002 e 2003, tomados conjuntamente

\begin{tabular}{lc}
\hline Custos variáveis & $337.915,69$ \\
Custos fixos & $277.874,24$ \\
Remuneração do capital semi- & $53.221,19$ \\
fixo & \\
Custos totais & $669.011,12$ \\
Valor da produção & $467.919,23$ \\
Margem bruta & $130.003,54$ \\
Margem bruta / ha & 650,02 \\
Retorno do capital de giro & 38,47 \\
Margem líquida & $-201.091,89$ \\
Margem líquida / ha & $-1.005,46$ \\
Custo variável unitário & 0,36 \\
Custo fixo unitário & 0,30 \\
Custo semi-fixo unitário & 0,06 \\
Custo total unitário & 0,71 \\
Preço de mercado unitário & 0,50 \\
\hline
\end{tabular}

Então a constatação que se faz é que existe uma tendência de déficit na atividade leiteira. E não parece justo atribuir apenas aos produtores a incumbência da adoção de medidas no intuito de revertê-la. Vejam-se, por exemplo, as Fig. 1 e 2 , que retratam o comportamento da produção leiteira e do preço recebido pelo produto. Note-se uma tendência dos preços a declinarem-se, especialmente após o mês de setembro. Ou seja, exatamente a partir do momento em que a atividade poderia compensar parte dos investimentos realizados no período da seca e de formação de cota. Poder-se-ia supor que o declínio dos preços se desse em função do aumento da produção neste período, superando o montante da cota e, assim, sendo entregue ao laticínio na rubrica de extracota. A Fig. 1 mostra o contrário, isto é, redução da produção, ajuste racional à debilitação dos preços.

De acordo com as curvas de produção (Fig. 1), constata-se que o volume produzido aumentou significativamente após a implantação do programa de acompanhamento da propriedade. Em que pese o desestímulo via preços, conforme apontado acima, a partir do ano 2000 a produção praticamente triplicou, atingindo o máximo em 2001, e daí decrescendo progressivamente até 2003. A melhor visualização desse aspecto desencorajador da política de preços é obtida tomando-se simultaneamente o comportamento das curvas de produção e preço do ano 2001.

A Fig. 3 apresenta os valores dos custos e preços unitários de cada período, corrigidos para dezembro de 2003. Essa operação constituiu um esforço para permitir a comparação tanto dos preços quanto dos custos ao longo dos anos da pesquisa, bem como o cotejo dessas duas grandezas entre si no decorrer do mesmo período.

Nota-se que não é apenas no cômputo geral que a atividade é deficitária. Em todos os períodos pesquisados, a receita foi inferior às despesas, indicando um processo histórico na relação de troca desfavorável entre o setor de produção e o industrial. Tomando por base os índices econômicos (Índices..., 2004), pode afirmar-se que a tendência decrescente observada na magnitude dos custos constitui o resultado do empenho do proprietário no sentido de racionalizar a atividade, e não um decréscimo nos custos dos fatores de produção. Esses indicadores retratam a variação de preços entre agosto de 1994 a abril de 2004, que em termos globais acusam uma inflação acumulada de $203,2 \%$. 


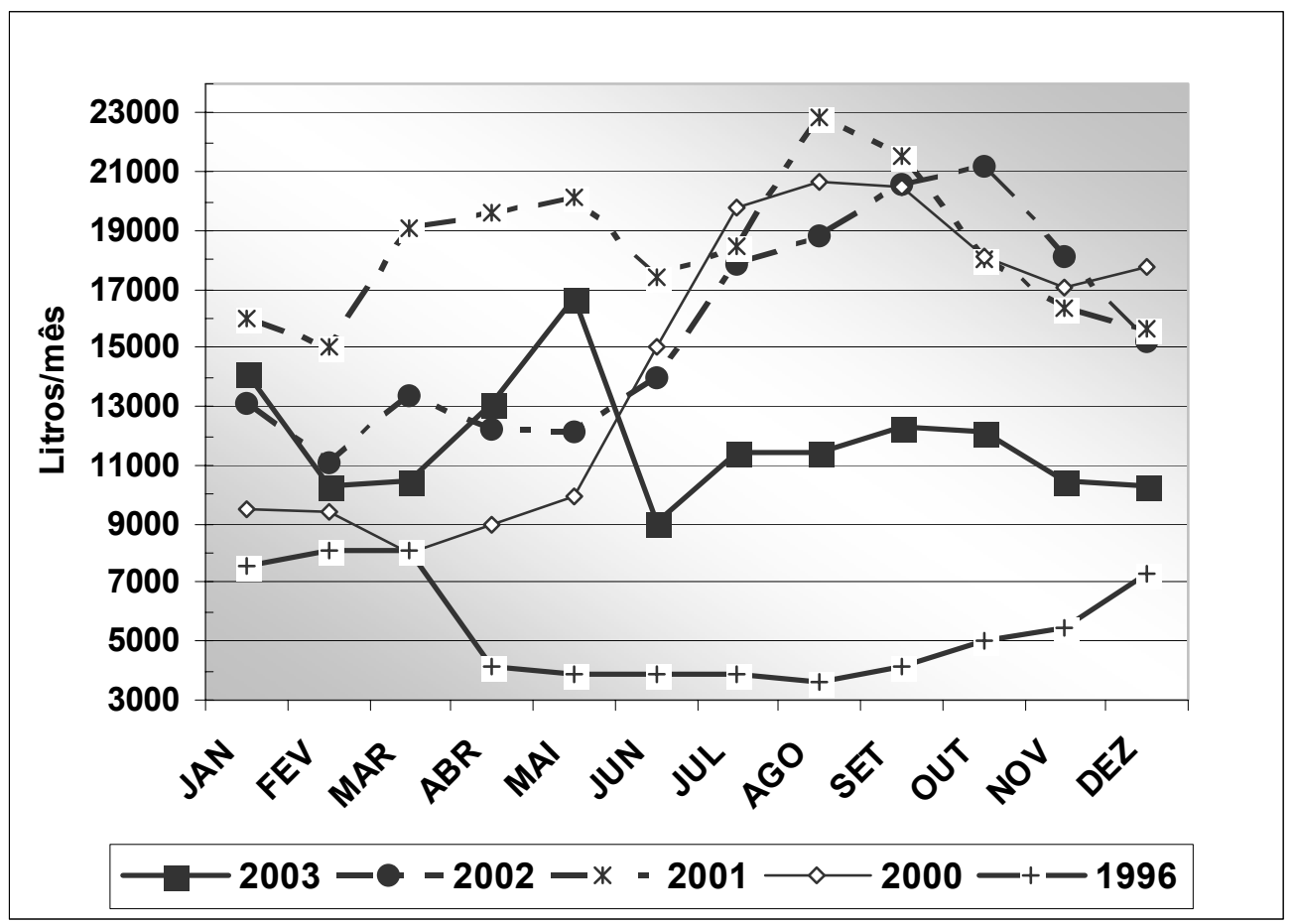

Figura 1. Produção de leite bovino da Fazenda Águas Limpas, município de Jaboticatubas-MG, relativa aos anos de 1996, 2000, 2001, 2002 e 2003.

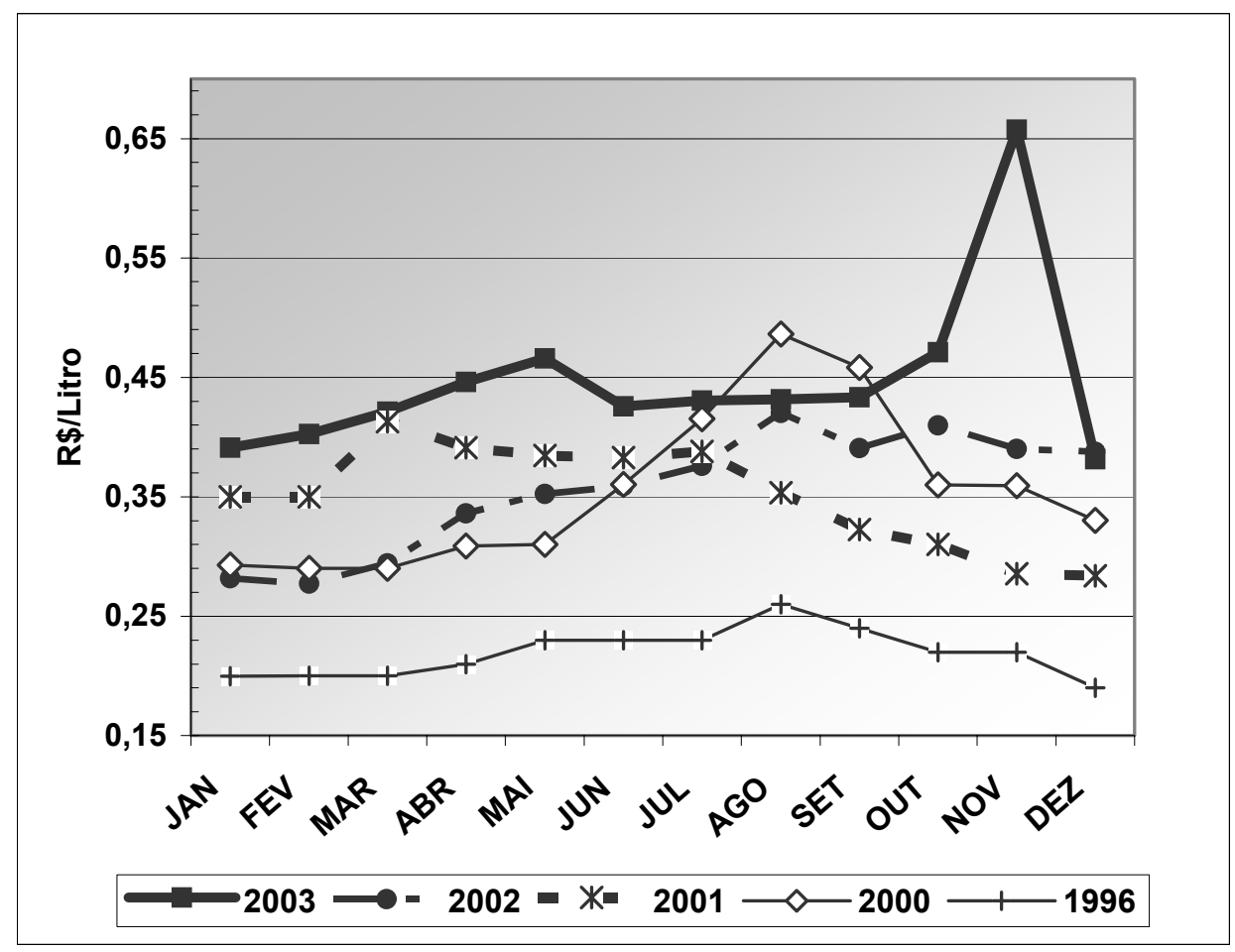

Figura 2. Preços recebidos pelo litro de leite bovino - Fazenda Águas Limpas, município de Jaboticatubas-MG, nos anos de 1996, 2000, 2001, 2002 e 2003. 


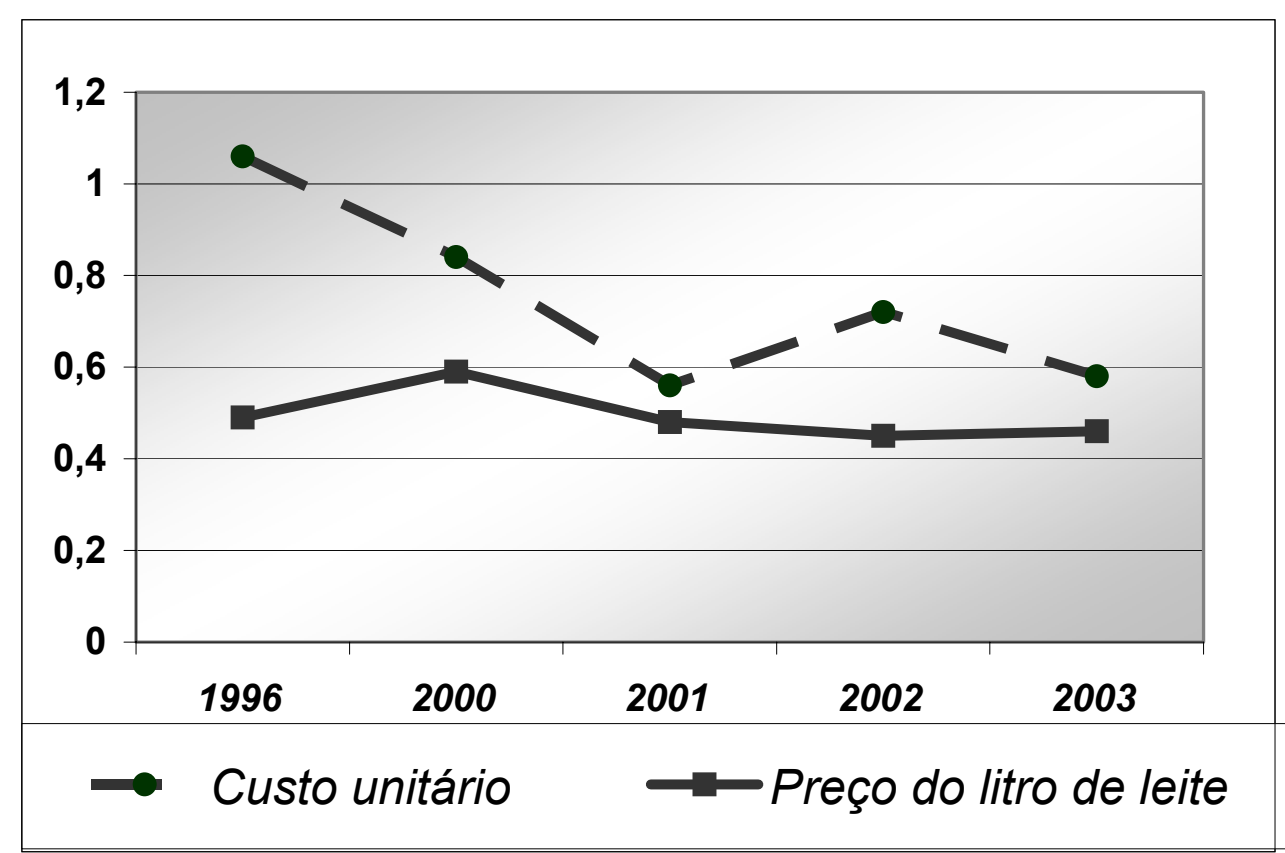

Figura 3. Custos de produção e preços recebidos pelo litro de leite bovino, na Fazenda Águas Limpas, município de Jaboticatubas-MG, nos anos de 1996, 2000, 2001, 2002 e 2003.

De acordo com esses mesmos indicadores, os produtos industriais destinados à produção agropecuária sofreram majoração de $226,4 \%$ em seus preços. Sal, rações e outros tiveram variação de 297,3\%; fertilizantes, 279,4\%; máquinas agrícolas, 240,9\%; combustível, 227,2\%. O quadro de variações fica mais interessante se a ele se contrapuser a alíquota referente ao leite: $83,3 \%$. Observa-se, portanto, que, enquanto os fatores de produção da atividade leiteira figuraram-se muito acima da inflação, o produto leite manteve-se extremamente distanciado daquele patamar. Diante dessa disparidade, quem foram os beneficiários do processo de racionalização verificado na atividade? A indústria? O consumidor? O governo? As políticas públicas? Ao proprietário coube apenas a façanha de ter reduzido a margem de prejuízos, e isso não é suficiente numa atividade empresarial.

Veja-se, entretanto, a situação particular da propriedade analisada, quanto à variação do preço do leite. Não obstante a flutuação dos preços recebidos no curso de cada ano analisado, esses mantiveram-se relativamente estáveis ao longo de todos os períodos, significando que, neste caso particular, não se distanciaram da variação da inflação. Isso ocorreu em virtude dos ganhos auferidos em forma de bônus, em função de melhorias empreendidas na atividade, como a introdução do tanque de expansão, ordenhadeira mecânica e outras práticas que favoreceram a melhoria da qualidade do produto. Nota-se que mesmo realizando investimentos, os fatores de produção subindo além da inflação, ainda assim, alcançou-se êxito em reduzir custos.

\section{CONCLUSÕES}

A atividade leiteira na propriedade analisada é inviável economicamente. Os resultados, avaliados durante cinco anos, demonstraram que os preços de mercado não cobrem os custos de produção. Enquanto se gastou $\mathrm{R} \$ 0,71$ para produzir um litro de leite, o preço recebido pelo produtor atingiu apenas $\mathrm{R} \$ 0,50$. A mão-de-obra foi o ítem que mais onerou os custos $(29,6 \%)$, como também o fator que elevou a margem dos custos fixos $(47,8)$, em relação aos valores dos custos variáveis $(48,7)$. A positividade da margem bruta ( $\mathrm{R} \$ 130.003,54)$ só foi útil no curto prazo. A descapitalização crescente, demonstrada pela margem líquida negativa ( $\mathrm{R} \$$ 201.091,89), inviabilizou o negócio e obrigou a reconversão. 


\section{REFERÊNCIAS BILIOGRÁFICAS}

GUIMARÃES, P.H.S.; MADALENA, F.H. Comparação econômica entre a produção de fêmeas F1 Holandês-Gir e algumas alternativas de produção de gado de corte por meio de simulação. 2003. 45f. Dissertação (Mestrado em Medicina Veterinária) - Escola de Veterinária, Universidade Federal de Minas Gerais, Belo Horizonte.

ÍNDICES econômicos. Conj. Econom., v.58, p.20-29, 2004.
PRADO, E.; CRUZ. F.E.R.; VIANNA, F.C. et al. Avaliação de desempenho técnico econômico de explorações leiteiras em Divinópolis-MG, segundo a forma de produção. Arq. Bras. Med. Vet. Zootec., v.47, p.361-372, 1995.

REIS, D.L. Estudo técnico-econômico da propriedade rural. Belo Horizonte: EMATERMG, 1996. 212p.

REIS, R.P. Custos de produção da atividade leiteira na região sul de Minas Gerais. Rev. Adm. UFLA, v.3, p.45-52, 2001. 